\title{
BMJ Open Quality Ensuring administration of first dose of antibiotics within the golden hour of management in neonates with sepsis
}

\author{
Somosri Ray, Venkataseshan Sundaram, Sourabh Dutta, Praveen Kumar (1)
}

To cite: Ray S, Sundaram V, Dutta S, et al. Ensuring administration of first dose of antibiotics within the golden hour of management in neonates with sepsis. BMJ Open Quality 2021;10:e001365. doi:10.1136/ bmjoq-2021-001365

Received 23 January 2021 Accepted 15 May 2021

\begin{abstract}
Administration of first dose of antibiotics within the golden hour in infants with sepsis is critical. Delays can increase mortality. During our observations as part of antibiotic stewardship programme in inborn neonatal unit, we found a significant delay in the administration of first dose of antibiotics from the decision time. We set up a quality improvement team to improve the proportion of neonates with sepsis, who received first dose of antibiotics within 1 hour of decision, from $0 \%$ to $80 \%$ over 2 months. We included inborn neonates requiring initiation or upgradation of antibiotics for a diagnosis of sepsis, from 1 May to 30 November 2018. We assessed the root causes behind delayed administration and found the lack of immediate availability of blood culture bottles, lack of awareness and busy clinical area as the major contributors to the delays in first dose. Various change ideas like ensuring prior availability of blood culture bottles, sensitising nursing staff and resident doctors, utilisation of hospital attendants and sharing responsibility of drawing culture between team members were tested through plando-study-act (PDSA) cycles.

The proportion of neonates receiving first dose of antibiotics within 1 hour increased from $0 \%$ to $91 \%$ over the study period and was sustained at $92 \%$ after 6 months. There was a significant reduction in median (IQR) time interval between decision and first dose from $120(100-290)$ to $45(30-60) \min (p<0.001)$ and after 6 months, it further decreased to $30(30-45) \mathrm{min}$. We achieved significant improvement in administration of first dose of antibiotics within 1 hour of decision, by using system analysis and testing change ideas in sequential PDSA cycles.
\end{abstract}

\section{PROBLEM}

Neonatal deaths form an increasing proportion of under five deaths, from $40 \%$ in 1990 to $47 \%$ in $2018 .^{1}$ Global distribution of neonatal deaths in 2018 estimated sepsis to be responsible for $15 \%$ of mortality. ${ }^{1}$ In India, sepsis accounts for $20 \%$ of all neonatal deaths. ${ }^{2}$ A systematic review of global, regional and national causes of child mortality in developing countries identified infection as one of the major causes of neonatal deaths. ${ }^{3}$ Case fatality of culture positive neonatal sepsis was nearly $50 \%$ in the Delhi Neonatal Infection Study. ${ }^{4}$ A combined analysis of three hospital datasets from India estimated that 20\%-40\% of preterm neonatal deaths were attributed to sepsis. ${ }^{5}$ Neonatal sepsis also carries a significant risk for adverse neurodevelopmental outcomes, low mental and psychomotor development indices. ${ }^{6}$

Ours is a government tertiary care neonatal unit comprising 22 level III beds and 18 level II beds. In addition, we have 30-35 neonates sharing cots in a make-shift nursery, waiting for a neonatal intensive care unit (NICU) bed. Our hospital receives high-risk referrals from seven North Indian states, often in late stages and with complications. The increasing number of referrals, without proportionate increase in level III NICU beds has led to this scenario. The revised hour-1 bundle of the 'Surviving Sepsis Campaign' emphasised appropriate immediate management in the initial hours which is directly associated with improved outcomes. ${ }^{7}$ A nearmiss incident in our unit made us wonder if we were compliant to this guideline. A 4-dayold neonate was found in a gasping state in our make-shift nursery, but luckily survived. A review of records revealed that this neonate was noticed to have new onset respiratory distress 4 hours back and antibiotics were prescribed. However, the dose had not been administered as the nurse and the resident doctor became busy with resuscitation calls and other tasks. An audit of 20 cases revealed that none of the babies got the first dose of antibiotic within 1 hour of the decision.

We planned this initiative to improve the proportion of neonates with sepsis, who received first dose of antibiotics within 1 hour of decision, from a baseline of $0 \%$ to $80 \%$ over 2 months.

\section{BACKGROUND}

The Surviving Sepsis Campaign recommendations highlight the importance of timely administration of antibiotics within first hour to decrease mortality. ${ }^{78}$ Guidelines for children including neonates also reflect the need for timely antibiotics. ${ }^{9}{ }^{10}$ A prospective 
observational study on septic neonates in the USA found that delayed time to antibiotic administration was an independent risk factor for death and prolonged cardiovascular dysfunction. ${ }^{11}$ With each hour of delay, there is $8 \%-9 \%$ increase in mortality. ${ }^{12}{ }^{13}$ A significant correlation has also been demonstrated between timing of antimicrobials and time to clearance of bacteria. ${ }^{14}$

Since the implementation of first hour sepsis bundle, mortality and morbidity in both adult and paediatric populations with sepsis has decreased. ${ }^{15}{ }^{16}$ Quality improvement initiatives leading to significant reductions in time from decision to antibiotic initiation, and mortality have been described from developed countries. ${ }^{9}{ }^{17-19}$ Schmatz et $a l^{20}$ found insufficient vascular access, delayed diagnostic laboratory evaluation, lack of urgency and no stat order by physicians as main reasons for delays in antibiotic administration. They showed significant improvement in antibiotic administration time from a median 151 (91-206) to 87 (61-121) min, through targeted nursing education, improved utilisation of an electronic sepsis order set and focused communication among medical teams. Weiner et $a l^{21}$ targeted antibiotic availability and vascular access, and showed that ensuring stock of antibiotics in intensive care unit and intramuscular administration of antibiotic in absence of vascular access significantly shortened the time interval between decision and first dose with an impact on mortality and hospital stay. Duber et $a l^{17}$ demonstrated that an updated protocol highlighting appropriate regimen within the golden hour and a checklist for inventory management of antibiotics in the unit ensured timely and appropriate antibiotic administration. Blissinger found poor communication and organisational workflow as major obstacles for the delay and showed significant reduction of antibiotic delivery time in suspected neonatal sepsis from a median of $137.5 \mathrm{~min}$ to $75 \mathrm{~min}$ after introduction of Computerised Physician Order Entry (CPOE).$^{15}$ In contrast, Alison did not find CPOE to improve antibiotic administration times in newborns in a pre-post intervention comparative study. ${ }^{22}$ Natarajan et al reported a mean time 1 hour $51 \mathrm{~min}$ from the physician order to drug administration, with only $25 \%$ being within $\leq 1$ hour and $66 \%$ within $\leq 2$ hours, and found delay in physician's order verification by pharmacist to be the main cause. ${ }^{14}$

The international guidelines for paediatric and adult sepsis recommend that blood cultures should be drawn before antibiotic initiation and antibiotics should be administered within 1 hour of diagnosis. ${ }^{7823}$ It has been seen that the 'process of care' starting from decision to administration of antibiotic depends on logistics, the local system and knowledge, attitudes and practices of healthcare workers. ${ }^{24}$ In our unit, we found a huge gap between what we believed would be happening and what was actually happening at ground level. We followed the model for improvement propagated by Institute for Healthcare Improvement and used system analysis to understand the contextual factors causing this gap. ${ }^{25}$

\section{MEASUREMENTS}

We included inborn neonates with a diagnosis of sepsis, in whom antibiotic was either being initiated or upgraded. The primary outcome measure was proportion of neonates receiving first dose of antibiotic within 1 hour of decision. Secondary outcome measure was median time interval between decision and administration of first dose of antibiotic.

We collected baseline data from 20 consecutive neonates between 1 May and 15 May 2018 for whom decision to initiate antibiotics was taken. Following information was collected by interviewing concerned personnel, reviewing the round book, antibiotic prescription and nursing charts: (1) date and time of decision of antibiotic initiation or upgradation, (2) date and time of first dose administration. We found that none of the 20 infants received first dose of antibiotic within 1 hour of decision. The median (IQR) time interval was 120 (100-290) min.

During plan-do-study-act (PDSA) cycles, different process measures were used according to the interventions. (1) Fortnightly blood culture bottle stock, (2) proportion of blood culture bottles replaced by hospital attendants, (3) number of blood cultures drawn by nursing staff, (4) number of blood cultures drawn by back-up resident doctors. The resident doctors, hospital attendants and nurses were assigned the tasks of collecting the respective data.

Run-charts were used to display and interpret the serial measurements of outcome and process indicators and to study the impact of changes by using run chart rules. Normally distributed variables were compared by unpaired ' $t$ '-test after evaluating equality of variance by Levene's test (F test). Skewed variables like time from decision to first dose were compared by Mann-Whitney $\mathrm{U}$ test. Proportions were compared by $\chi^{2}$ test. We followed the SQUIRE 2.0 guidelines for reporting. ${ }^{26}$

\section{DESIGN}

We executed the following steps to achieve the aim of improving the proportion of neonates with sepsis, who received first dose of antibiotics within 1 hour of decision, from a baseline of $0 \%$ to $80 \%$ : (a) forming a quality improvement team of nursing officers, resident doctors, faculty of paediatrics and microbiology, and hospital attendants, (b) measuring baseline rates of practice to administer first dose antibiotic within 1 hour of decision, (c) finding possible reasons for delayed initiation by process flow charting (figure 1), fish-bone analysis (figure 2) and selecting the most important ones with help of Pareto chart (figure 3), (d) conducting PDSA cycles to test change ideas generated by the team and (e) continuing post-intervention audits.

The following facts were realised regarding the existing system: (1) there was no well-defined system of maintaining stock of blood culture bottles-majority of time attendants were asked to procure the bottle from the lab, accounting for delay in drawing blood culture and 


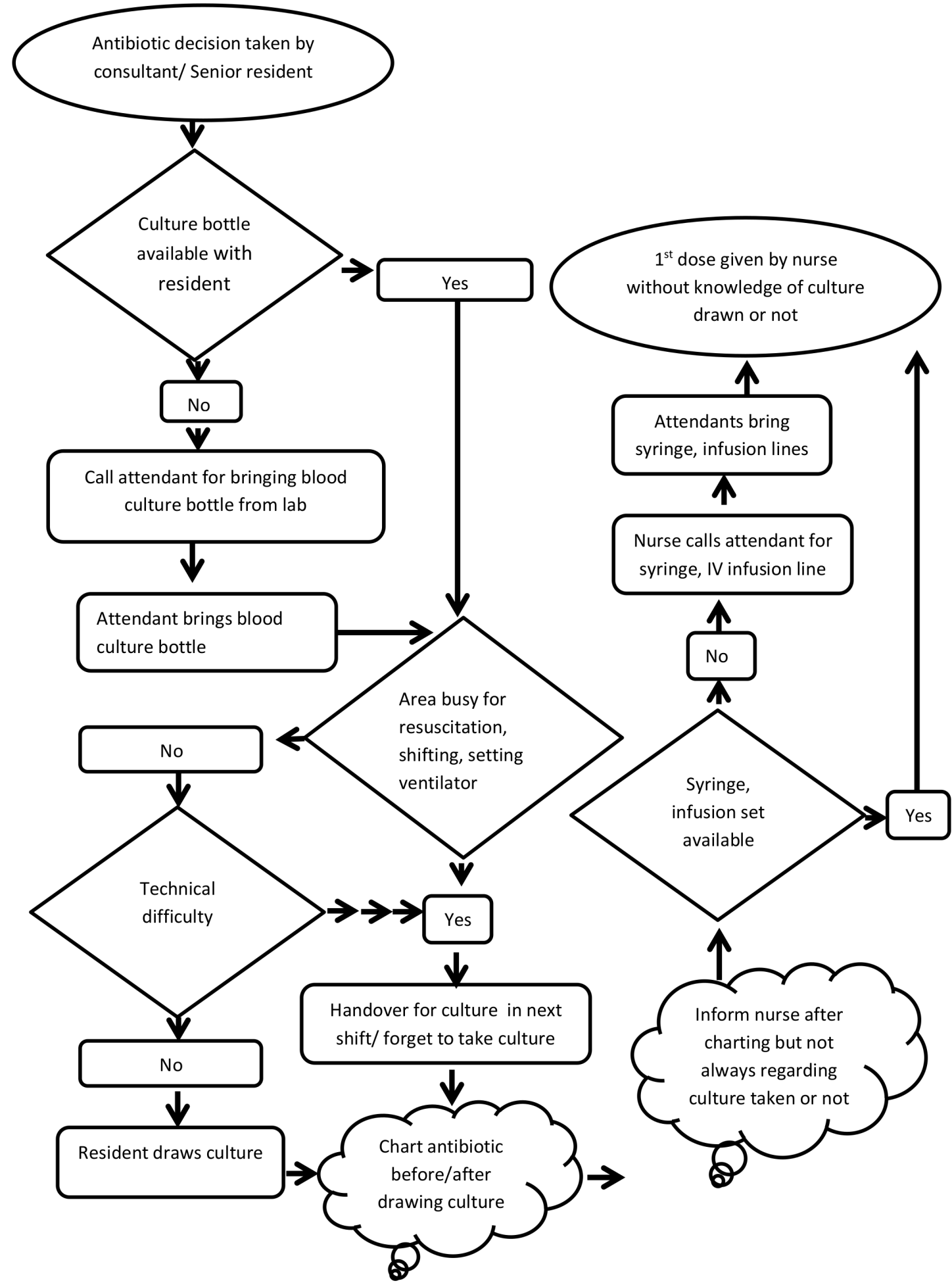

Figure 1 Process flow chart from decision to administration of first dose of antibiotic.

contributing to major delay in antibiotic administration, (2) lack of complete understanding among nurses and residents about the importance of administering the dose within 1 hour of decision, (3) resident doctors were usually busy in resuscitation and respiratory stabilisation in a high-load high-turnover set-up, (4) inadequate communication between nurses and residents regarding treatment decision and whether blood culture had been drawn or not, (5) technical difficulties to draw blood culture in small neonates. Presence of intravenous access did not come up as an issue, probably because of 24-hour coverage by senior residents and experienced nursing staff. There was ample and regular supply of antibiotics and this also did not emerge as a problem.

Since delays in drawing blood culture and preoccupation of healthcare workers with acute care emerged 


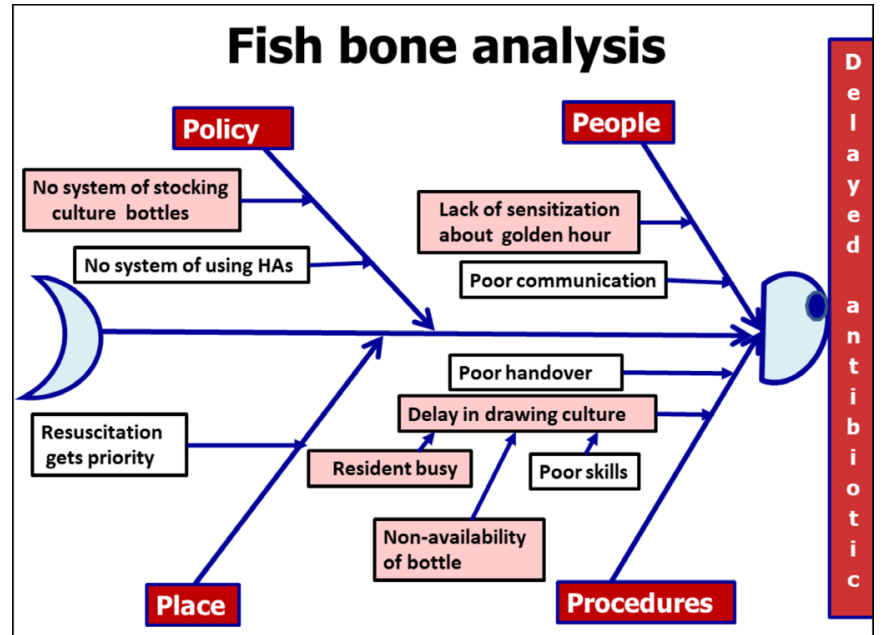

Figure 2 Fish-bone analysis for the problem of delay in administration of first dose of antibiotic. HA, Hospital attendant.

as the major bottlenecks, the quality improvement team involved microbiologists, resident doctors, nurses and hospital attendants. The interventions described in table 1 were targeted at ensuring that a blood culture bottle and a trained person are always available so that the culture is drawn and the antibiotic dose given within 1 hour.

\section{STRATEGY}

We used multiple PDSA cycles to test and refine the interventions (table 1). The project team met at the end of each cycle to review data and discuss next action steps.

There were two major targets of the changes tested in the PDSA cycles: having prior availability of blood culture bottles and ensuring timely draw of culture before antibiotic administration. For ensuring prior availability of culture bottle, of the several things which were tried, reorganising the work schedule of hospital attendants and giving them this responsibility under the supervision of nurses worked successfully. It was noted that in many cases, resident doctors drew blood culture late because of being busy in attending deliveries, resuscitation or setting-up respiratory support. This was tackled by training and empowering the nurses to take blood culture sample and organising a system of back-up resident doctor from another area if the nurses were also busy. The schedule of hospital attendants and motivational posters encouraging team spirit were displayed prominently. In PDSA1 and in subsequent cycles as well (figure 4), we also focused on awareness regarding unit antibiotic policy and importance of antibiotic timing during nursing staff education through power point presentation, sharing educational material through whatsapp, email and posters. During the first 3 days of rotational monthly posting of resident doctors in the unit, orientation sessions regarding importance of timely antibiotic administration, need for blood culture draw before antibiotic administration, video demonstration of procedure of drawing blood culture, organising the culture bottle, its labelling and deposition in laboratory and charting of antibiotics were conducted by the members of the quality improvement team. An objective evaluation of effectiveness of these sessions was done periodically with a brief questionnaire.

\section{Implementation and spread of intervention}

From 1 August 2018, implementation of the following measures was taken along with fortnightly audit for the sustenance of the improvement: (1) stock maintenance of blood culture bottle by hospital attendants under nursing supervision, (2) empowering nursing staff to draw blood culture before first dose of antibiotic if resident doctor was busy, (3) ensuring back-up resident doctor during busy

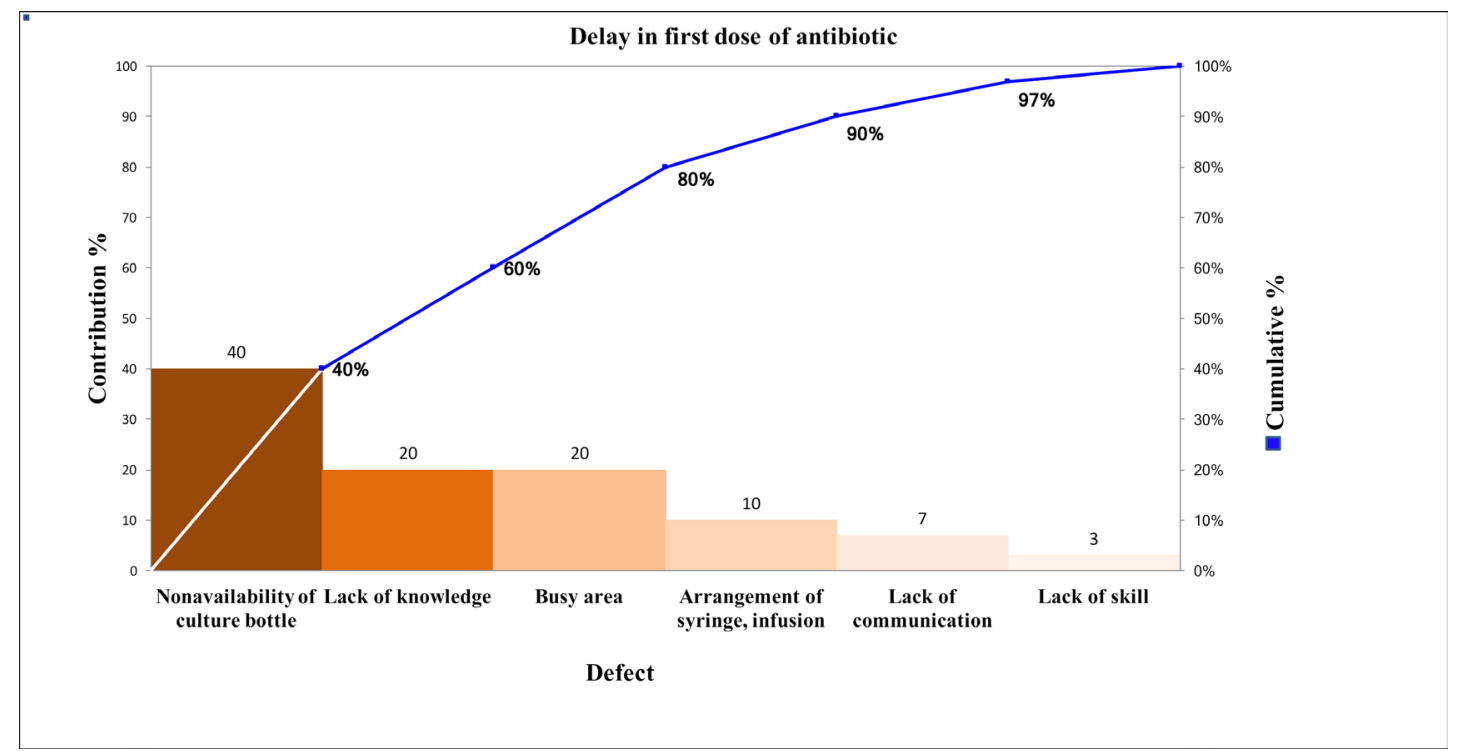

Figure 3 Pareto chart highlighting non-availability of culture bottle, lack of knowledge and busy area being major contributors to delay in first dose of antibiotic. 


\begin{tabular}{|c|c|c|c|c|c|}
\hline $\begin{array}{l}\text { PDSA } \\
\text { cycle }\end{array}$ & $\begin{array}{l}\text { When } \\
\text { (dd/mm/yy) }\end{array}$ & Plan & Do & Study & Act \\
\hline $\begin{array}{l}2 \\
(n=15)\end{array}$ & 16/06/18-30/06/18 & $\begin{array}{l}\text { (1) Utilisation of parent } \\
\text { attendant for one to one } \\
\text { replacement of culture } \\
\text { bottle while submitting in } \\
\text { microbiology lab. } \\
\text { (2) Using pre-printed } \\
\text { identification stickers on } \\
\text { culture bottle and culture } \\
\text { form for avoiding data } \\
\text { errors. }\end{array}$ & $\begin{array}{l}\text { (1) Call parent } \\
\text { attendant and explain } \\
\text { the location of } \\
\text { microbiology lab to } \\
\text { submit the inoculated } \\
\text { culture bottle and bring } \\
\text { back replacement. } \\
\text { (2) Handover of culture } \\
\text { bottle stock between } \\
\text { nursing shifts. } \\
\text { (3) Ensuring availability } \\
\text { of pre-printed } \\
\text { identification stickers } \\
\text { at the time of making } \\
\text { patient file. } \\
\text { (4) Continuing } \\
\text { educational activities } \\
\text { and tracking of } \\
\text { decision to dosing time } \\
\text { as in PDSA1. }\end{array}$ & $\begin{array}{l}\text { (1) Antibiotics were } \\
\text { started or upgraded } \\
\text { in } 15 \text { neonates, blood } \\
\text { culture drawn in all } \\
15 . \\
\text { (2) Out of } 15 \text { bottles } \\
\text { consumed, only } \\
\text { five were replaced } \\
\text { leading to rapidly } \\
\text { diminishing stock. } \\
\text { It was found that } \\
\text { parent attendants } \\
\text { had difficulty in } \\
\text { understanding the } \\
\text { instructions and were } \\
\text { not waiting at the lab } \\
\text { till new bottle was } \\
\text { handed over to them. } \\
\text { (3) Compliance for } \\
\text { timely antibiotic } \\
\text { administration was } \\
8 / 15 \text { (53\%). } \\
\text { Resident doctors } \\
\text { being busy in } \\
\text { resuscitations and } \\
\text { fixation of CPAP } \\
\text { circuits, resulted } \\
\text { in delayed draw of } \\
\text { cultures and delayed } \\
\text { first dose in busy } \\
\text { hours. }\end{array}$ & $\begin{array}{l}\text { Drop the idea of } \\
\text { sending culture } \\
\text { bottles through } \\
\text { parent attendants, } \\
\text { find alternative } \\
\text { ways to maintain } \\
\text { culture bottle stock. } \\
\text { Find alternatives of } \\
\text { drawing cultures } \\
\text { during busy hours. }\end{array}$ \\
\hline
\end{tabular}




\begin{tabular}{|c|c|c|c|c|c|}
\hline $\begin{array}{l}\text { PDSA } \\
\text { cycle }\end{array}$ & $\begin{array}{l}\text { When } \\
\text { (dd/mm/yy) }\end{array}$ & Plan & Do & Study & Act \\
\hline $\begin{array}{l}3 \\
(n=14)\end{array}$ & 01/07/18-14/07/18 & $\begin{array}{l}\text { (1) Using hospital } \\
\text { attendants for sending } \\
\text { culture bottles by } \\
\text { rescheduling their } \\
\text { activities. } \\
\text { (2) Task-shifting during } \\
\text { busy hours to avoid } \\
\text { delays in drawing } \\
\text { cultures. } \\
\text { (3) Continue educational } \\
\text { sessions and data } \\
\text { tracking as before. }\end{array}$ & $\begin{array}{l}\text { (1) Schedules of } \\
\text { hospital attendants } \\
\text { for deposition and } \\
\text { replacement of culture } \\
\text { bottles including lab } \\
\text { timings on weekdays } \\
\text { and holidays were } \\
\text { displayed as posters in } \\
\text { each patient care area. } \\
\text { At beginning of every } \\
\text { shift, a nurse informed } \\
\text { the hospital attendants } \\
\text { regarding this activity. } \\
\text { (2) Nurses were } \\
\text { empowered to draw } \\
\text { blood culture if delay } \\
\text { was anticipated due to } \\
\text { resident doctor being } \\
\text { busy. } \\
\text { Proportions of blood } \\
\text { cultures drawn } \\
\text { by nurses were } \\
\text { recorded. Team work } \\
\text { was encouraged by } \\
\text { motivational posters. }\end{array}$ & $\begin{array}{l}\text { (1) Antibiotics were } \\
\text { started or upgraded } \\
\text { in } 14 \text { neonates, blood } \\
\text { culture drawn in all } \\
14 . \\
\text { (2) Out of } 14 \text { bottles } \\
\text { consumed } 13 \text { (95\%) } \\
\text { were replaced by } \\
\text { hospital attendants. } \\
\text { (3) Compliance for } \\
\text { timely antibiotic was } \\
64 \% \text {. Three (21\%) } \\
\text { blood cultures were } \\
\text { drawn by nurses. } \\
\text { It was noted that in } \\
\text { busy hours and at } \\
\text { time of overcrowding, } \\
\text { often both nurses } \\
\text { and resident doctor } \\
\text { remained occupied } \\
\text { in respiratory } \\
\text { stabilisation, } \\
\text { resuscitation, } \\
\text { admission and } \\
\text { transfer of neonates } \\
\text { to respective areas. }\end{array}$ & $\begin{array}{l}\text { Explore alternative } \\
\text { plans for } \\
\text { management } \\
\text { during busy hours. }\end{array}$ \\
\hline $\begin{array}{l}4 \\
(n=23)\end{array}$ & 15/07/18-31/07/18 & $\begin{array}{l}\text { (1) Assign back-up } \\
\text { resident doctor. } \\
\text { (2) Education, tracking } \\
\text { and other successful } \\
\text { measures of previous } \\
\text { PDSAs to continue. }\end{array}$ & $\begin{array}{l}\text { (1) Assign back-up } \\
\text { resident doctor from } \\
\text { another relatively quiet } \\
\text { area to draw cultures if } \\
\text { required. } \\
\text { (2) Proportion of } \\
\text { cultures drawn by } \\
\text { back-up resident and } \\
\text { nurses were recorded. } \\
\text { Appreciation and } \\
\text { encouragement of } \\
\text { team work was done } \\
\text { sharing the compliance } \\
\text { data in whatsapp } \\
\text { groups and monthly } \\
\text { unit party. }\end{array}$ & $\begin{array}{l}\text { (1) Antibiotics were } \\
\text { started or upgraded } \\
\text { in } 23 \text { neonates, blood } \\
\text { culture drawn in all } \\
23 \text {. } \\
\text { (2) Out of } 23 \text { bottles } \\
\text { consumed } 23 \text { (100\%) } \\
\text { were replaced by } \\
\text { hospital attendants. } \\
\text { (3) Compliance for } \\
\text { timely antibiotic was } \\
91 \% \text {. Four (17\%) } \\
\text { blood cultures were } \\
\text { drawn by nurses and } \\
\text { five }(21 \%) \text { by back- } \\
\text { up resident doctor. }\end{array}$ & $\begin{array}{l}\text { Written policy } \\
\text { and SOPs were } \\
\text { finalised for } \\
\text { timely antibiotic } \\
\text { administration. } \\
\text { Periodic monitoring } \\
\text { plans (fortnightly } \\
\text { audit) for } \\
\text { compliance and } \\
\text { any unexpected } \\
\text { problems were } \\
\text { made. }\end{array}$ \\
\hline
\end{tabular}

CPAP, continuous positive airway pressure; ICU, intensive care unit; PDSA, plan-do-study-act; SOP, standard operating procedure.

hours, (4) ongoing education and sensitisation regarding the importance of timely administration of antibiotics.

\section{RESULTS}

The rate of first dose antibiotic administration within 1 hour of decision, increased from $0 \%$ to $91 \%$ over the study period (figure 4). There was a significant reduction in median (IQR) time interval between decision and first dose from $120(100-290)$ to $45(30-60)$ min $(\mathrm{p}<0.001)$ (table 2).

At end of PDSA1, although $100 \%$ of culture bottle stock was maintained, and there was significant improvement in the timely administration of first dose to $47 \%$, microbiology department could not sustain the bottle stock. After the modifications in the process, in subsequent PDSA cycles 2, 3 and 4, the process measures were as follows: bottle stock maintenance-33\%, 95\% and $100 \%$, respectively, culture drawn by nurses-17\%-21\%, cultures drawn by back-up residents $-21 \%$.

Initially there was resistance from nurses to take part in drawing the cultures, but they became enthusiastic soon after orientation sessions and understanding the importance of drawing culture before start of antibiotic and giving the first dose within 1 hour. Hospital attendants 


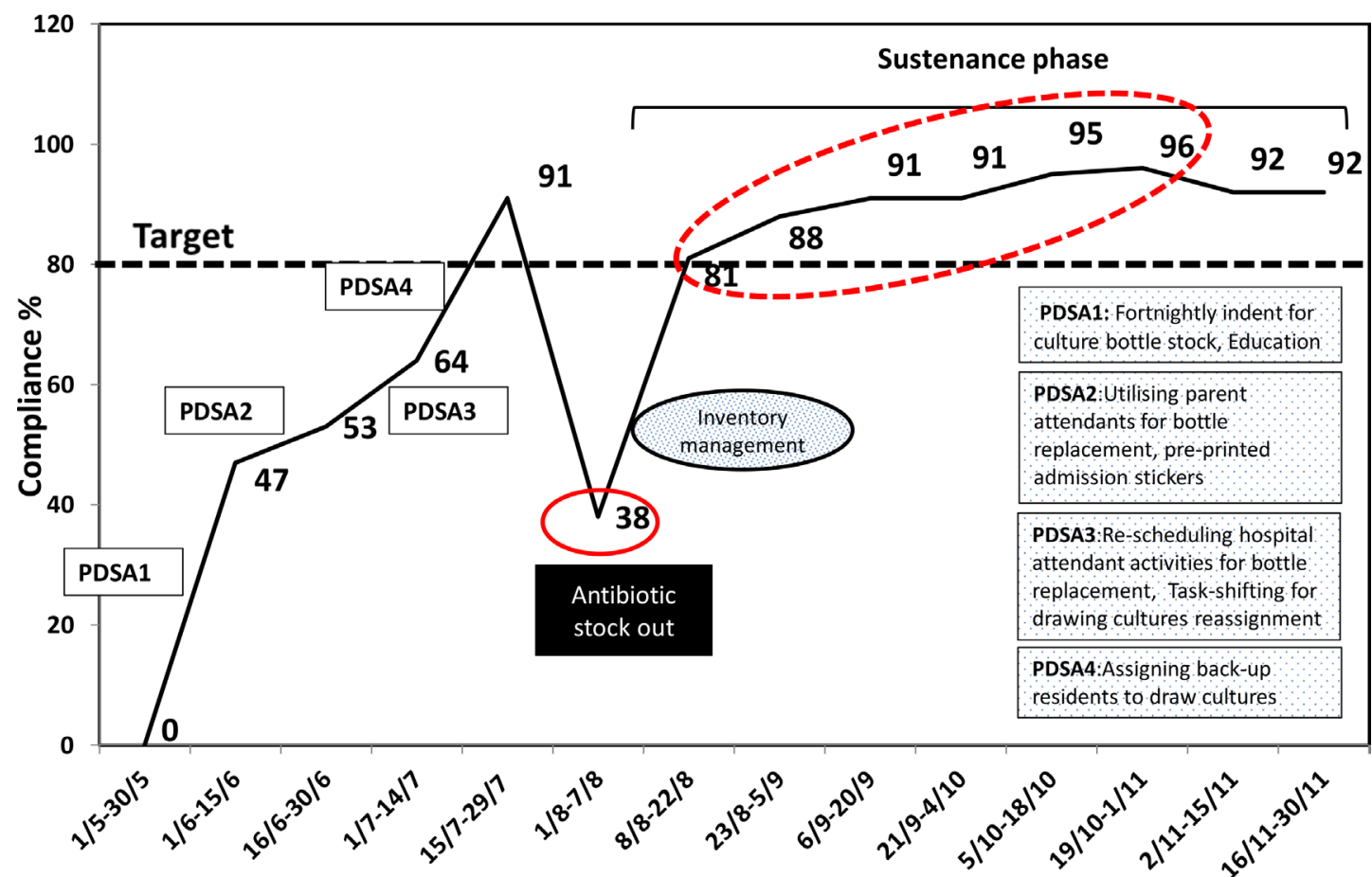

Figure 4 Summary of all PDSAs along with sustenance phase-the small red oval indicates an astronomical point due to special cause variation, while the dashed red oval indicates five or more sequential data points all going up. PDSA, plan-dostudy-act.

also initially resisted as culture bottle deposition and replacement appeared to be an extra burden in their daily work schedule. Reorganisation of work schedule of hospital attendants worked well for all.
During sustenance phase, it was found that the time interval between decision and first dose administration of antibiotic suddenly increased to median 125 (60-180) min and compliance to administration of dose in first

Table 2 Results of PDSA cycles and subsequent fortnightly audits of time from decision for first dose of antibiotic and drawing of blood culture before it

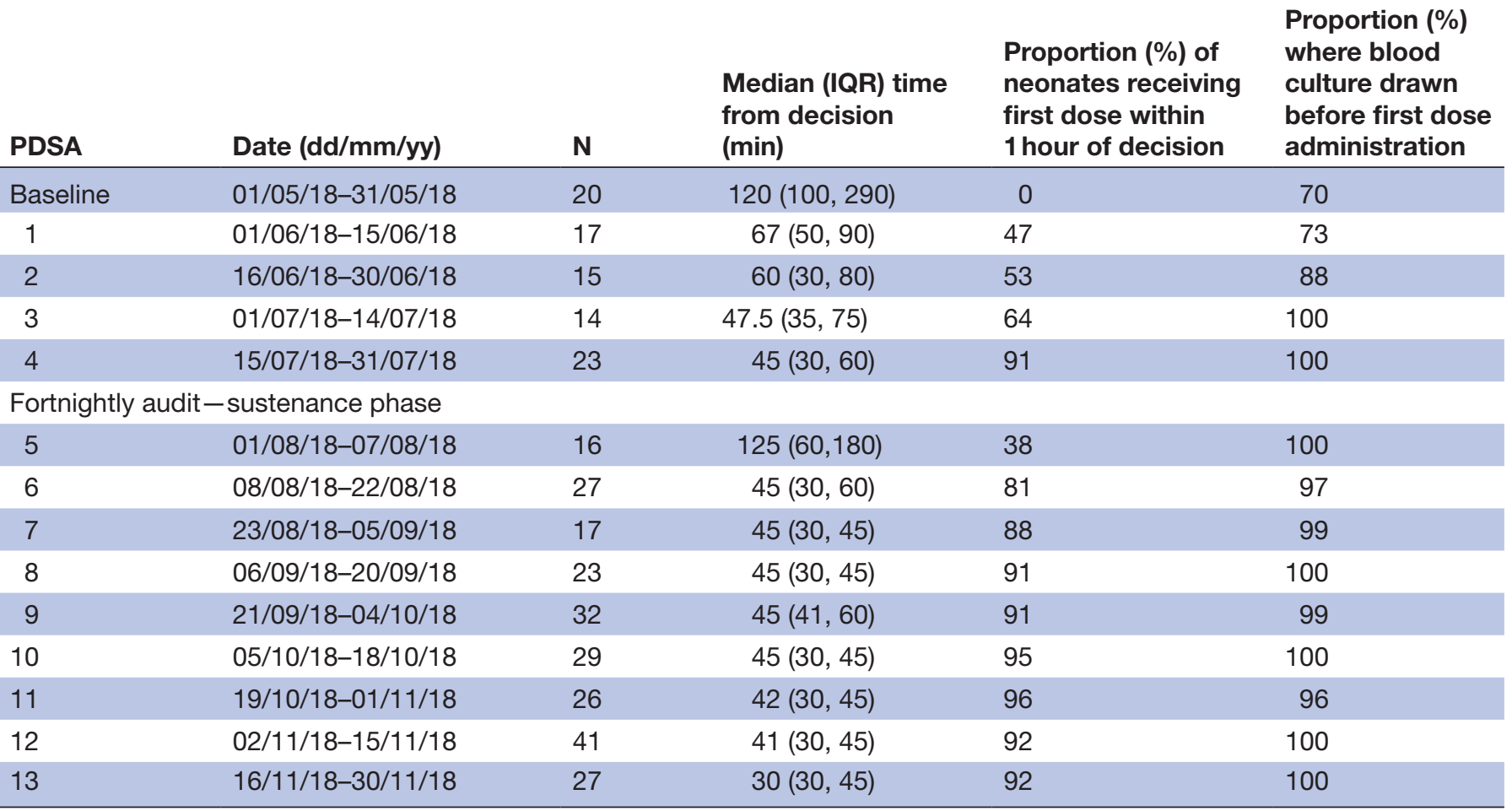

PDSA, plan-do-study-act. 
hour dropped to $38 \%$ (table 2). On probing, a special cause variation was found in antibiotic stock-out, as the hospital rate contract had not been renewed and family attendants had to procure antibiotics from market. Hence on priority, stock of antibiotics for next 2 weeks was arranged immediately through donations. In addition, inventory management of antibiotics was reviewed and a standard operating procedure was made for anticipating and tackling such situations in future in collaboration with the hospital pharmacy. Subsequent audits revealed better compliance and at end of 6 months, the proportion of antibiotic doses administered within 1 hour persisted above $90 \%$. The median time interval from decision to first dose further decreased to $30(30-45) \mathrm{min}$ (table 2).

To sustain the continued improvement, the project team handed over the responsibility of regular audit, supervision, orientation sessions and addressing any issues in a timely manner to a designated faculty and senior resident of the unit.

\section{LESSONS AND LIMITATIONS}

We stumbled across an unidentified and unanticipated problem during the course of our efforts to improve antibiotic stewardship. Many times, deficiencies in certain activities remain hidden, because they are not part of routine audits. Once found, we devoted full attention and energy, and tackled it systematically using the principles of quality improvement. Of the basic methods of system analysis, mapping of the process of antibiotic administration was the most revealing. It not only informed us where the delays were but also revealed that the process of antibiotic administration was actually quite complex and dependent on multiple stakeholders. Process mapping is an excellent tool for problems related to time delays.

A key lesson learnt was that prioritisation of the root causes to be targeted is of extreme importance during the phase of problem analysis. As demonstrated in the Pareto chart of our report, timely draw of blood culture before starting the antibiotic was the major bottleneck contributing to delayed antibiotic administration. We overlooked the importance of antibiotic stock, as there was an ample supply and stock of antibiotics during baseline data collection phase. We learnt that parts of the system which may be functioning very well currently can also breakdown at a future time. Therefore, a theoretical analysis of all the steps of a process is also needed apart from the feedback derived from flow chart and fish-bone analysis. While each PDSA test cycle was executed with certain assumptions, we encountered several new problems. However, as we had set up a team with representation from all stakeholders, the members came out with new solutions. The importance and equal status given to all the members for their roles helped the team to stay motivated. It was natural for nurses and hospital attendants to resist taking on the new work responsibilities. However, since they were members of the team trying to modify the system and were convinced of its benefits for the patients, they adapted to the changes and actually started enjoying the changes.

We could not measure and analyse the impact of this process improvement on mortality and morbidity. However, we believe the link between timely administration of antibiotic and patient outcomes is well proven.

Scenarios of overcrowding and mismatch between patient load and manpower are quite common across the developing world. We believe such occurrences are quite common but hidden or ignored, or assumed to be not manageable. Our experience will be useful for several others struggling with similar problems.

\section{CONCLUSION}

We were able to significantly reduce the time from decision to actual administration of first dose of antibiotics in neonates with sepsis and improve the proportion of neonates receiving the dose within the first hour. This was achieved through an analysis of the local system and testing of process changes through sequential PDSA cycles, without any additional resources.

Twitter Praveen Kumar @praveenpginicu

Acknowledgements This study could not have been accomplished without the ongoing support and dedication of nursing staff, resident doctors and hospital attendants of the neonatal unit.

Contributors SR has substantial contribution in acquisition and analysis of data, drafting the manuscript and final approval of the version to be published, and agreement to be accountable for all aspects of the work in ensuring that questions related to the accuracy or integrity of any part of the work. VS and SD have substantial contribution in conception, analysis of data, critical revision of the manuscript, final approval of the version to be published and agreement to be accountable for all aspects of the work in ensuring that questions related to the accuracy or integrity of any part of the work. PK has substantial contribution in design of the work, interpreting the data, revising it critically for important intellectual content, critical revision of the manuscript and final approval of the version to be published and agreement to be accountable for all aspects of the work in ensuring that questions related to the accuracy or integrity of any part of the work. All authors performed QI as part of their regular assigned roles.

Funding Publication of this article is made Open Access with funding from the Nationwide Quality of Care Network.

Competing interests None declared.

Patient and public involvement Patients and/or the public were not involved in the design, or conduct, or reporting, or dissemination plans of this research.

Patient consent for publication Not required.

Ethics approval The project was initiated after institutional ethics committee approval. A waiver of individual consent was obtained. We implemented evidencebased strategies at the system level. No alterations were made in the management of individual patients.

Provenance and peer review Not commissioned; externally peer reviewed.

Data availability statement All data relevant to the study are included in the article.

Open access This is an open access article distributed in accordance with the Creative Commons Attribution Non Commercial (CC BY-NC 4.0) license, which permits others to distribute, remix, adapt, build upon this work non-commercially, and license their derivative works on different terms, provided the original work is properly cited, appropriate credit is given, any changes made indicated, and the use is non-commercial. See: http://creativecommons.org/licenses/by-nc/4.0/.

ORCID iD

Praveen Kumar http://orcid.org/0000-0003-4742-8787 


\section{REFERENCES}

1 United Nations Inter-agency Group for Child Mortality Estimation. Levels and trends of child mortality report 2019. Available: https:// www.unicef.org/ media/60561/file/UN-IGME-child-mortality-report2019.pdf [Accessed 24 Dec 2020].

2 Sankar MJ, Neogi SB, Sharma J, et al. State of newborn health in India. J Perinatol 2016;36:S3-8. Dec.

3 Liu L, Oza S, Hogan D, et al. Global, regional, and national causes of child mortality in 2000-13, with projections to inform post-2015 priorities: an updated systematic analysis. Lancet 2015;385:430-40.

4 Chaurasia S, Sankar MJ, Agarwal R, et al. Characterisation and antimicrobial resistance of sepsis pathogens in neonates born in tertiary care centres in Delhi, India: a cohort study. Lancet Glob Health 2016;4:e752-60.

5 Jain K, Sankar MJ, Nangia S, et al. Causes of death in preterm neonates ( $<33$ weeks) born in tertiary care hospitals in India: analysis of three large prospective multicentric cohorts. J Perinatol 2019;39:13-19.

6 Stoll BJ, Hansen NI, Adams-Chapman I, et al. Neurodevelopmental and growth impairment among extremely low-birth-weight infants with neonatal infection. JAMA 2004;292:2357-65.

7 Levy MM, Evans LE, Rhodes A. The surviving sepsis campaign bundle: 2018 update. Intensive Care Med 2018;44:925-8.

8 Rhodes A, Evans LE, Alhazzani W, et al. Surviving sepsis campaign: international guidelines for management of sepsis and septic shock: 2016. Intensive Care Med 2017;43:304-77.

9 Polin RA, the Committee on fetus and newborn. Management of neonates with suspected or proven early-onset bacterial sepsis. Pediatrics 2012;129:1006-15.

10 WHO. Recommendations for management of common childhood conditions, 2017. Available: https://apps.who.int/iris/bitstream / handle/10665/44774/9789241502825_eng.pdf [Accessed 24 Dec 2020].

11 Schmatz M, Srinivasan L, Grundmeier RW, et al. Surviving sepsis in a referral neonatal intensive care unit: association between time to antibiotic administration and in-hospital outcomes. J Pediatr 2020;217:59-65.

12 Pines JM. Timing of antibiotics for acute, severe infections. Emerg Med Clin North Am 2008;26:245-57.

13 Garnacho-Montero J, Aldabo-Pallas T, Garnacho-Montero C, et al. Timing of adequate antibiotic therapy is a greater determinant of outcome than are TNF and IL-10 polymorphisms in patients with sepsis. Crit Care 2006;10:1-12.
14 Natarajan G, Monday L, Scheer T, et al. Timely empiric antimicrobials are associated with faster microbiologic clearance in preterm neonates with late-onset bloodstream infections. Acta Paediatr 2014;103:e418-23.

15 Herrán-Monge R, Muriel-Bombín A, García-García MM, et al. Epidemiology and changes in mortality of sepsis after the implementation of surviving sepsis campaign guidelines. J Intensive Care Med 2019;34:740-50.

16 Evans IVR, Phillips GS, Alpern ER, et al. Association between the new York sepsis care mandate and in-hospital mortality for pediatric sepsis. JAMA 2018;320:358-67.

17 Duber HC, Hartford EA, Schaefer AM, et al. Appropriate and timely antibiotic administration for neonatal sepsis in Mesoamérica. BMJ Glob Health 2018;3:e000650.

18 Bissinger RL, Mueller M, Cox TH, et al. Antibiotic timing in neonates with suspected hospital-acquired infections. Adv Neonatal Care 2013;13:22-8.

19 Brierley J, Carcillo JA, Choong K, et al. Clinical practice parameters for hemodynamic support of pediatric and neonatal septic shock: 2007 update from the American College of critical care medicine. Crit Care Med 2009;37:666-88.

20 Schmatz M, Perez A, Srinivasan L. Timing of antibiotic administration in neonatal sepsis: evaluating current practices and initiating quality improvement. Abstract AAP NCE, 2015. Available: https://aap. confex.com/aap/2015/webprogram/Paper30445.Html [Accessed 20 Dec 2020].

21 Weiner GM, Barks JD, Wright EJ, et al. Improving the timing of antibiotic administration to high-risk newborns. J Perinatol 1998;18:230-3.

22 Chapman AK, Lehmann CU, Donohue PK, et al. Implementation of computerized provider order entry in a neonatal intensive care unit: impact on admission workflow. Int J Med Inform 2012;81:291-5.

23 Miller JM, Binnicker MJ, Campbell S, et al. A guide to utilization of the microbiology laboratory for diagnosis of infectious diseases: 2018 update by the infectious diseases Society of America and the American Society for microbiology. Clin Infect Dis 2018;67:813-6.

24 Metersky ML. Community-Acquired pneumonia: process of care studies. Curr Opin Infect Dis 2002;15:169-74.

25 Institute of Healthcare Improvement. Model for improvement. Available: http://www.ihi.org/resources/Pages/Howtolmprove/default. aspx [Accessed 14 Dec 2020].

26 Ogrinc G, Davies L, Goodman D, et al. SQUIRE 2.0 (standards for quality improvement reporting excellence): revised publication guidelines from a detailed consensus process. BMJ Qual Saf 2016;25:986-92. 